\title{
Anticipation in familial intracranial aneurysms in consecutive generations
}

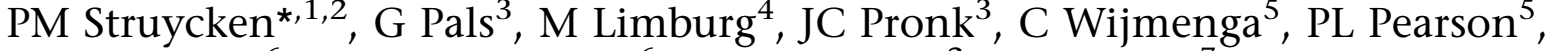 \\ JAFM Luijten $^{6}$, JSP van den Berg ${ }^{6}$, M Vermeulen $^{2}$, GJE Rinkel $^{7}$ and A Westerveld ${ }^{1}$
}

\begin{abstract}
${ }^{1}$ Department of Human Genetics, Academic Medical Center, Universiteit van Amsterdam, The Netherlands; ${ }^{2}$ Department of Neurology, Academic Medical Center, Universiteit van Amsterdam, The Netherlands; ${ }^{3}$ Department of Human Genetics, Vrije Universiteit Amsterdam, The Netherlands; ${ }^{4}$ Department of Clinical Informatics, Academic Medical Center, Universiteit van Amsterdam, The Netherlands; ${ }^{5}$ Department of Human Genetics, Universiteit van Utrecht, The Netherlands; ${ }^{6}$ Department of Neurology, University Hospital Nijmegen, The Netherlands; ${ }^{7}$ University Department of Neurology, Utrecht, The Netherlands
\end{abstract}

Intracranial aneurysms (IA) are the major cause of subarachnoid haemorrhages (SAH). A positive family history for $\mathrm{SAH}$ is reported in $5-10 \%$ of the patients. The mode of inheritance is not unambiguously established; both autosomal dominant and recessive modes have been reported. In sporadic as well as in familial SAH, approximately $60 \%$ of the SAH patients are female. Recently, anticipation has been described in familial SAH. Since up to $15 \%$ of the SAHs are not caused by an IA, we have analysed anticipation, sex ratio and mode of inheritance only in families with patients with a proven IA in two consecutive generations. A total of $\mathbf{1 0}$ families were studied in which at least two persons in consecutive generations were affected by SAH, a symptomatic IA (SIA) or a presymptomatic IA (PIA). We also analysed published data from families with a proven IA in two consecutive generations on age of SIA onset and sex ratios among affected family members (both SIA and PIA). The age of SIA onset in the parental generation (mean 55.5 years) differed significantly from the age of onset in their children (mean $\mathbf{3 2 . 4}$ years). In the parental generation 11 men and 37 women were affected (both SIA and PIA), in the consecutive generation these numbers were 28 men and 32 women. There is a significant difference in sex ratio of affected family members when the generations are compared $(P<0.02)$. No family could be found in which three consecutive generations were affected by an IA (SIA or PIA).

European Journal of Human Genetics (2003) 11, 737-743. doi:10.1038/sj.ejhg.5201039

Keywords: familial intracranial aneurysm; anticipation

\section{Introduction}

Cardiovascular diseases including subarachnoid haemorrhage $(\mathrm{SAH})$ are a leading cause of death in the industrialised countries. An SAH is fatal in up to $50 \%$ of the cases, although a decline in case fatality rate has been observed over the past decade. Many of the surviving patients have moderate to severe neurological deficits. ${ }^{1}$ The incidence of SAH varies between seven and 20 per

*Correspondence: Dr PM Struycken, Gerg en Dalseweg 278, CM Nijmegen 6522, The Netherlands. E-mail: patrick.struycken@arboned.nl Received 22 August 2002; revised 4 April 2003; accepted 15 April 2003
100000 persons per year and approximately $10 \%$ of the patients report a positive family history. ${ }^{2,3}$ Bromberg et al suggested that SAH in the consecutive generations occurred at an earlier age as compared to previous generations. In both sporadic and in familial cases SAH occurs more frequently in women than in men. ${ }^{4}$ This difference is attributed to the higher occurrence of an SAH in women over 50 years of age in the sporadic cases. ${ }^{5}$ Lozano found a sex ratio difference $(\mathrm{M}: \mathrm{F}=75: 100)$ for all ages in pedigrees irrespective of the mode of inheritance. ${ }^{4}$

Intracranial saccular aneurysms (IAs) are responsible for $85 \%$ of $\mathrm{SAH}^{6}{ }^{6}$ As based on autopsy studies about $2-3 \%$ of 
the population has an asymptomatic IA, in familial cases the prevalence is estimated at $9.5-10.5 \%{ }^{3}$ Over 200 families have been described since the first report on the familial occurrence of IA was presented by Chambers in $1954 .^{7,8}$ Segregation analysis did not reveal one mode of inheritance, both autosomal recessive (AR) and autosomal dominant $(\mathrm{AD})$ patterns of inheritance have been described. ${ }^{7,9}$

In our study, we included only families with at least two relatives in two consecutive generations affected by IA. Anticipation was studied only in families with SIA in consecutive generations. All proven IAs irrespective of symptoms were included in the study of the sex ratios.

\section{Materials and methods}

Families were included in this study only after the diagnosis of a symptomatic IA (SIA), a presymptomatic IA (PIA) or an intracranial aneurysm without information on the symptoms (IA) in at least two relatives in consecutive generations had been proven by radiological, preoperative or post-mortem investigations. Aneurysms were designated symptomatic when either an SAH had occurred or neurological impairment was caused by the aneurysm. Families were excluded when aneurysms were associated with other intracranial vascular or known heritable diseases (eg arteriovenous malformation, AD polycystic kidney disease, Marfan syndrome). Among 50 families ascertained for a genetic analysis 10 showed the disease in two consecutive generations. In addition, we searched the literature for families in which SIA, PIA or IA were shown in two consecutive generations. PMS and ML reviewed the data on the families presented as well as those from the literature.

We performed an extensive Medline search from 1966 onward with keywords aneurysm, cerebral, intracranial, familial, genetic(s) and subarachnoid haemorrhage to identify studies published between 1966 and 1999. The reference lists of all retrieved publications were scrutinised for additional family studies. This method of crosschecking was continued until no further publications were found. Either the most recent or the most extensive publication was used or data from several publications were combined avoiding counting patients twice when more than one report on the same family was identified.

The age of onset was determined only in SIA (thus excluding PIA and IA). We performed a first analysis (to avoid ascertainment errors) in those families in which several children were affected. Index patients were excluded and only the eldest affected child was included for the analysis.

On the basis of the results of this first analysis, anticipation was studied in all families known to date showing SIA in consecutive generations.

The age of onset distribution in the consecutive generations was evaluated with the Kolmogorov-Smirnoff test.
The mean difference was calculated for the age of onset analysis comparing the generations. The mean age of onset was used in the analysis when multiple children were affected within a sibship (except for the first analysis in which only the eldest affected child was used). Differences in age of onset between generations and between genders for both generations were tested with a paired $t$-test. All SIA, PIA and IA patients were included in the sex ratio analysis. The sex ratio variation was analysed by a $\chi^{2}$-test. The statistical analyses were performed using SPSS for Windows, release 7.5.2.

\section{Results}

The pedigrees of the 10 families with SAH, SIA and/or PIA in two consecutive generations are depicted in Figure 1. One family (Figure 1j) has been published before, but additional data are presented in this paper., ${ }^{3,10-12}$ In all, two fathers, eight mothers, eight sons and 10 daughters were affected in those families. No family was found with affected relatives in three consecutive generations, as is exemplary shown in family $\mathrm{J}$.

Anticipation, the phenomenon that the disease becomes manifest at an earlier age in the next generations, is apparent for SAH in the presented families (Figure $1 \mathrm{a}, \mathrm{b}, \mathrm{c}$, $e, h$ and $j$ ). In six families, IA (SIA and PIA) were confirmed in both generations (Figure 1a, b, c, d, i and j). Two fathers with two sons and four mothers with five sons and four daughters were affected in these families.

SIA occurred in both generations in four of our families (Figure 1a, b, c and j), and in these families anticipation was established: The mean difference in age of onset between the generations was 21.2 years $(P<0.003$; paired $t$-test; $t=9.180)$.

We reviewed the literature for families in which the diagnosis is SIA and/or PIA was evident in two consecutive generations to underline our observation on anticipation. We analysed all these families known to date with affected members in consecutive generations (Table 1a SIA families). When more than one child in one family was affected their mean age was used (the test was performed only on families from the literature: Table 1A minus Struycken's cases). The mean difference in age of onset between the generations was 23.0 years $(P<0.0001$; paired $t$-test; $t=11.137)$.

For all families, the mean age of onset in the parents was 55.5 years (SD 12.5). There is no significant difference in the age of onset between fathers and mothers (two-tailed $t$-test; $P=0.25)$. The mean age of onset in the children was 34 years (SD 11.2). No significant difference in the age of onset between daughters and sons was observed (two-tailed $t$-test, $P=0.54)$. The mean difference between the generations was 22.4 years $(P<0.0001$; paired $t$-test; $t=12.913)$. To avoid ascertainment bias and to underline the anticipation found in our own families anticipation was tested on a 

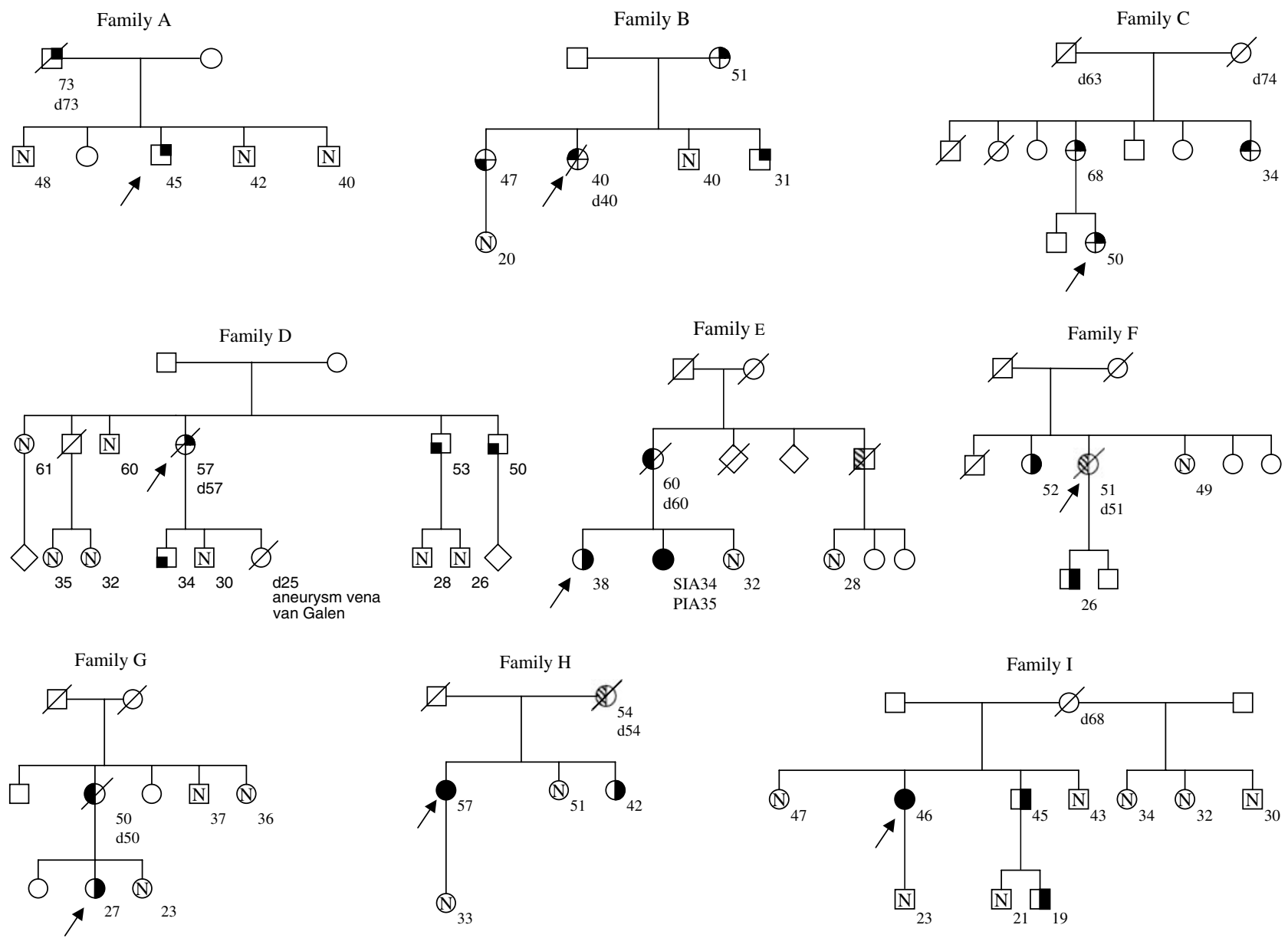

amily $\mathrm{H}$
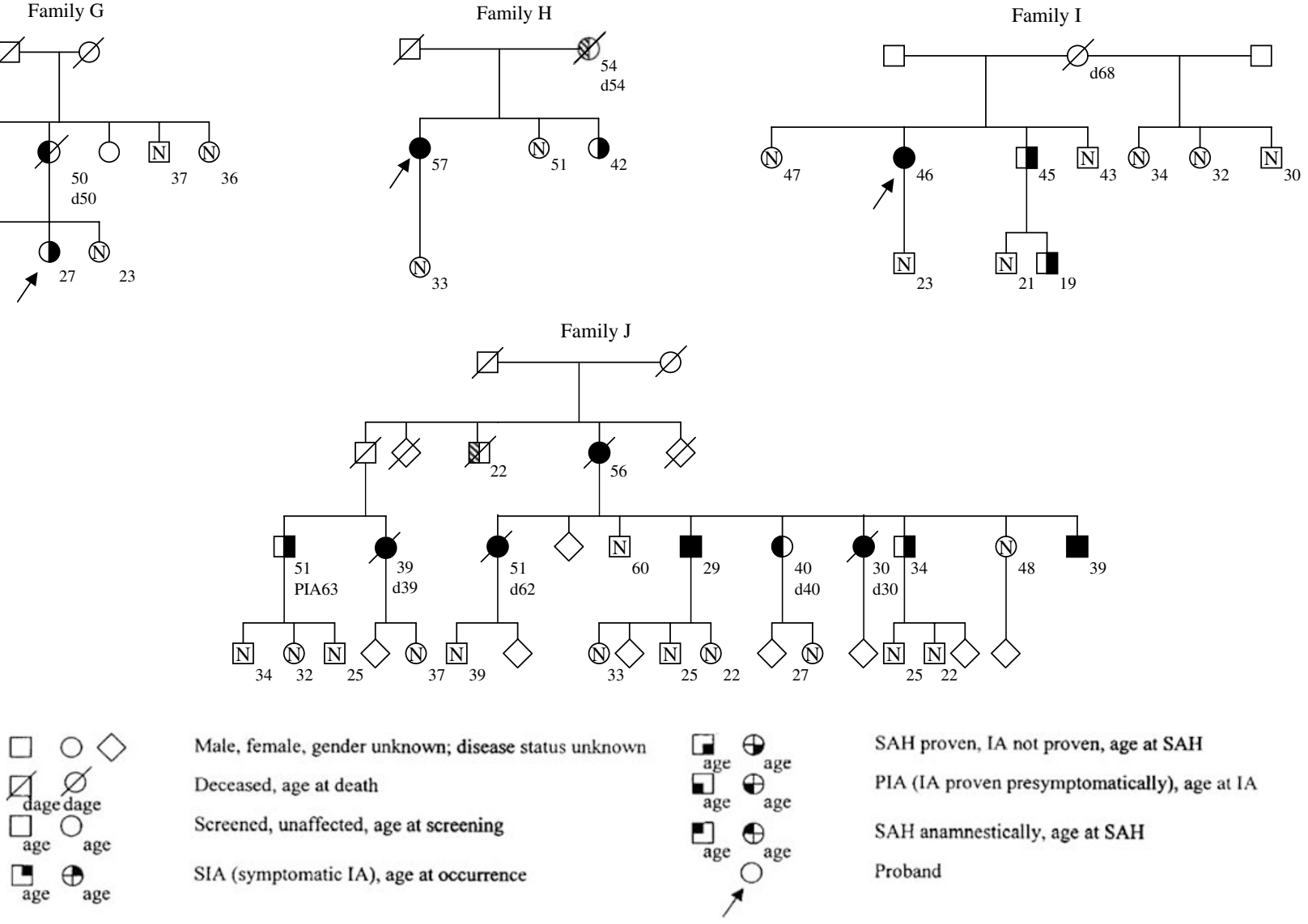

SAH proven, IA not proven, age at SAH

PIA (IA proven presymptomatically), age at IA

SAH anamnestically, age at SAH

Proband

Figure 1 (a-i) Newly presented families with SAH and/or IA in consecutive generations. (1j) Family previously reported with additional data. Data shown on age of onset (SIA), age at detection (PIA, IA), age at screening (when negative). Sequences of individuals in families altered and individuals not taking part in the GAIA study are omitted for privacy reasons. 
Table 1 Families described in this paper and families described previously. (a) SIA and (b) SIA/PIA/IA in consecutive generations

Author, number of family in original paper

Parent: sex, SIA age at detection

(a) SIA in consecutive generations Bentzen $^{24 *}$

Verdura et $a l^{25 *}$

Struycken 1-J ${ }^{10,11,26 *}$

Edelsohn et $a l^{27 *}$

Struycken 1-B*

Shinton et $a l^{28}$

Brisman ${ }^{41}$

Acosta-Rua et al 29

Evans et $a \beta^{30}$

Brodsky et $a \beta^{31}$

Elshunnar and Whittle ${ }^{32}$

Bromberg et al $4^{3}$ (GJER)

Chakravorty and Gleadhill $1^{33}$

Chakravorty and Gleadhill $2^{33}$

Nagae et $a l^{34}$

Morooka and Waga ${ }^{35}$

Maroun et al $2^{36}$

Chambers et $a l^{8}$

Jaksche ${ }^{37}$

Maroun et al $1^{36}$

Ambrosetto and Galassi ${ }^{38}$

Struycken 1-A

Struycken 1-C

(b) $S I A / P I A / I A$ in consecutive generations

Patrick and Appleby ${ }^{21}$

Jain $1^{39}$

Jain $2^{39}$

Ronkainen et al $6^{14}$

Ronkainen et al $8^{14}$

Ronkainen et al $14^{14}$

Ronkainen et al $15^{14}$

Ronkainen et al $25^{14}$

Ronkainen et al $38^{14}$

Ronkainen et al $39^{14}$

Ronkainen et al $45^{14}$

Ronkainen et al $48^{14}$

Ronkainen et al $56^{14}$

Ronkainen et al $70^{14}$

Ronkainen et al $73^{14}$

Ronkainen et al $75^{14}$

Ronkainen et al $84^{14}$

Ronkainen et al $88^{14}$

Leblanc et al A 40

Leblanc et al $\mathrm{C}^{40}$

Leblanc et al $\mathrm{D}^{40}$ o, SIA 35*
ㅇ, $\operatorname{SIA~} 67^{*}$
, SIA 75*
ㅇ, SIA 56*

ㅇ, SIA $51^{*}$

ธ., SIA 54

ᄋ, SIA 28

+, SIA 62

+, SIA 59

\%, SIA 38

, SIA 53

, SIA 68

ๆ, SIA 62

+, SIA 42

\%, SIA 66

, SIA 66

․ SIA 60

o, SIA 52

ô, SIA 45

ठิ, SIA 54

ô, SIA 43

Oे, SIA 73

ᄋ, SIA 68

ธิ, PIA 41

\%, IA 62

ㅇ, IA 43

๙ิ, IA 51

ơ, IA 73

, IA 69

\%, IA 35

, IA 42

․ IA 45

, IA 61

\%, IA 90

o, IA 67

․ IA 46

क, IA 79

+, IA 56

ㅇ, IA 71

\%, IA 73

ᄋ, IA 65

ㅇ, IA 68

ㅇ, IA 39

, IA 55
Child(ren): sex, SIA, age of onset/PIA, age at detection/IA, age at diagnosis

$$
\begin{aligned}
& \text {, SIA } 44^{*} \\
& \text {, SIA } 40 \\
& \text { o, SIA 56* } \\
& \text { o, SIA } 42 \\
& \text { o, SIA } 40 \\
& \text { ․, SIA } 51^{*} \\
& \text { ․, SIA } 30 \\
& \text { ô, SIA } 29 \\
& \text { ô, SIA } 39 \\
& \text { o, PIA } 34 \\
& \text { ऊ, SIA 25* } \\
& \text { \%, SIA } 21 \\
& \text { ․ SIA } 24 \\
& \text { ㅇ, PIA } 30 \\
& \text { 0, SIA 31* } \\
& \text { ㅇ, PIA } 47 \\
& \text { } \text {, SIA } 21 \\
& \text { o, SIA } 25 \\
& \text { ○, SIA } 29 \\
& \text { +, SIA } 25 \\
& \text { ․ SIA } 18 \\
& \text {, SIA } 44 \\
& \text {, SIA } 48 \\
& \text { O., SIA } 34 \\
& \text { oิ, SIA } 15 \\
& \text { o., SIA } 48 \\
& \text { o, SIA } 28 \\
& \text { ô, SIA } 25 \\
& \text { o, SIA } 21 \\
& \text { o, SIA } 27 \\
& \text { o, SIA } 28 \\
& \text { ․ SIA } 35 \\
& \text { O., SIA } 45 \\
& \text { \&, SIA } 50
\end{aligned}
$$

ㅇ, SIA 15

o, IA 23

ᄋ, IA 19

ô, IA 25

ㅇ, IA 29

o, IA 37

+, IA 34

, IA 22

ô, IA 27

ㅇ, IA 26

, IA 55

o, IA 38

ㅇ, IA 24

, IA 49

ㅇ, IA 21

ᄋ, IA 23

․, IA 49

ô, IA 52

ㅇ, IA 36

\&, IA 24

, IA 31

ô, IA 33 
Table 1 Continued

\begin{tabular}{|c|c|c|}
\hline Author, number of family in original paper & $\begin{array}{l}\text { Parent: sex, SIA } \\
\text { age at detection }\end{array}$ & $\begin{array}{l}\text { Child(ren): sex, SIA, } \\
\text { age of onset/PIA, age at } \\
\text { detection/IA, age at diagnosis }\end{array}$ \\
\hline $\begin{array}{l}\text { Leblanc et al } \mathrm{H}^{40} \\
\text { Leblanc et al I } 40 \\
\text { Struycken } 1-\mathrm{D} \\
\text { Struycken } 1-\mathrm{I}\end{array}$ & $\begin{array}{l}\text { o, IA } 68 \\
\text { क, IA } 45 \\
\text { क, SIA } 57 \\
\text { o, PIA } 45\end{array}$ & $\begin{array}{l}\text { 9, IA } 45 \\
\text { o, IA } 39 \\
\text { o, PIA } 34 \\
\text { o, PIA } 19\end{array}$ \\
\hline
\end{tabular}

Sex, type of intracranial aneurysm (symptomatic intracranial aneurysm, SIA; presymptomatic intracranial aneurysm, PIA or proven intracranial aneurysm, unknown whether symptomatic or not IA) and age of onset, detection or diagnosis are shown. SIA depicted by * were used in the preliminary age of onset analysis. When more individuals were affected within a sibship the mean of the age of onset of SIA was calculated and is shown. When individuals are afflicted by more than one IA, the age at which the first IA was found is depicted.

subset of families in which the index patient was excluded in the test. Only the age of onset in oldest affected child (other than the index patient) and in the parents was analysed (families and persons used in this analysis are depicted with an asterix in Table 1a). Even under these restrictions, a significant age of onset difference (mean difference $=15.4$ years; $P=0.01$; paired $t$-test: $t=0.549$ ) was noted. Finally, the data were combined (data shown in Table 1a). The age distribution was shown to be normal in both generations (Kolmogorov-Smirnov test: $0.495<Z<0.796$ ). A difference in the age of onset between generations is shown. There is no evidence of proven IA in three consecutive generations in any family. Even in the large family (Figure $1 \mathrm{j}$ ) there are no indications for IA in the third generation.

The sex ratio of affected parents $(\mathrm{M}: \mathrm{F}=11: 37)$ is different $\left(\chi^{2}=6.52, P<0.02\right)$ from the sex ratio of their affected children $(\mathrm{M}: \mathrm{F}=28: 32)$. When sex ratios in both generations were compared with the general population (1:1.02 for the Netherlands), only the ratio in parents did differ (children: $\quad \chi^{2}=0.092, \quad P=0.76 ; \quad$ parents: $\quad \chi^{2}=12.49$, $P<0.001)$.

\section{Discussion}

A genetic predisposition for IA has been established. $3,7,13-15$ Also for IA evidence for a familial component has been suggested. ${ }^{11,13}$ The prevalence for IA is estimated between 2 and $3 \%$ in the general population. In familial cases, the prevalence is estimated at $9.5-10.5 \%$, with a relative risk of at least four for first-degree relatives. ${ }^{16-18}$ The high $(87.5 \%)$ concordance of IAs in monozygotic twins underlines the genetic basis (although data figures on dizygotic twins are not available). ${ }^{15}$

We have collected families with affected persons in two consecutive generations. This was necessary for the analysis of age of onset and sex ratio analyses between generations.

Anticipation is established for SIA even when only the age of onset of the oldest affected child (which was not the index patient) is compared with the age of onset in the parent. The anticipation is not related to the sex of the transmitting parent. SIA has never been found in three consecutive generations. This disappearance of the phenotype is clearly illustrated in a large Dutch family (Figure 1j). In the third generation no relative harboured an aneurysm over a 15-year follow-up period. Ages at screening varied from 25-39 years, being an age at which, in the light of the aforementioned anticipation, IAs should be present.

The occurrence of the disease in two consecutive generations in itself points towards an $\mathrm{AD}$ inheritance pattern. This is strengthened by other IA families in which at least half of the children were affected. ${ }^{10,19-21}$ But if AD inheritance holds in these selected families, how do we explain that no families are seen in which the disease is manifest in three consecutive generations? Is it due to anticipation and subsequent extinction? Although the data discussed so far clearly indicate that in these selected families the inheritance pattern is consistent with $\mathrm{AD}$ inheritance, be it with anticipation and extinction, strong arguments for AR inheritance are present as well. More than $75 \%$ of all IA families do not show affected individuals in consecutive generations. ${ }^{7}$ The number of affected children keeps far from the 50\% affected offspring as is observed in $\mathrm{AD}$ diseases. In our study, 40 of the 50 families did not show affected individuals in consecutive generations (data not shown). An argument for the contribution of recessive genes to the disease is the higher risk for siblings compared to children of a patient to harbour an aneurysm. ${ }^{22}$ Additional support comes from a family presented by Bromberg et $\mathrm{al}^{3}$ in which in a consanguineous marriage five out of 20 children are affected. In this particular case, a single defective disease gene may be present in homozygous state in all patients due to homozygosity by descent.

Pseudodominancy might explain observed anticipation and the absence of third generation affected family members in the families included in this study. The 
obvious AD inheritance is mimicked by homozygosity for a recessive IA gene in the parental generation. The presence of one heterozygous parent and one homozygous parent for the IA gene would then explain the occurrence of the disease in $50 \%$ of the offspring in some families. ${ }^{10,19-21}$

The development and the maintenance of the intracranial arteries as one entity suggest that one or more pathways, each containing several genes, showing either an $\mathrm{AD}$ or an $\mathrm{AR}$ inheritance, are involved. Especially, the development of cerebral artery bifurcations seems important since the apexes of these bifurcations are almost always involved in IAs. The IA phenotype is established depending on the steps in the pathway that are dysfunctioning. A polygenic model may explain all the observed phenomena. The sex ratio differences observed between generations are difficult to explain, but might be due to an over-representation of elderly affected women (as is seen in the sporadic cases) in the parental generation. ${ }^{23}$ However, no significant difference in the age of onset was found comparing both sexes in the parental generations.

It seems very unlikely that genomic imprinting, the epigenetic phenomenon in which the expression of genes is reversibly modified depending on the sex of the transmitting parents, has attributed to the observed phenomena of anticipation and sex ratios. No differences in anticipation were observed in the offspring of transmitting mothers and fathers. Besides, both females and males were found to be present in the paternal offspring and this also holds for the maternal offspring.

Our present effort is directed to the isolation and characterisation of the major genes contributing to IA. This will provide an insight into the mode of inheritance and will finally enable us to identify presymptomatically people at high risk for developing IA and subsequent SAH.

\section{Acknowledgements}

We thank the investigators from the MARS study, UW Huisman, $R$ Groen, and PJAM Brouwer, for referring families. This research is supported by a grant of the Netherlands Heart Foundation. (Grant no.: 96.103).

\section{References}

1 Hop JW, Rinkel GJE, Algra A, van Gijn J: Case-fatality rates and functional outcome after subarachnoid hemorrhage: a systematic review. Stroke 1997; 28: 660-664.

2 Linn FH, Rinkel GJE, Algra A, van Gijn J: Incidence of subarachnoid hemorrhage: role of region, year, and rate of computed tomography: a meta-analysis. Stroke 1996; 27: 625-629.

3 Bromberg JEC, Rinkel GJE, Algra A et al: Familial subarachnoid hemorrhage: distinctive features and patterns of inheritance. Ann Neurol 1995; 38: 929-934.

4 Lozano AM, Leblanc R: Familial intracranial aneurysms. J Neurosurg 1987; 66: 522-528.

5 Locksley HB: Natural history of subarachnoid hemorrhage, intracranial aneurysms and arteriovenous malformations. J Neurosurg 1966; 25: 321-368.
6 Warlow CP, Dennis MS, Gijn van J et al: What caused this subarachnoid haemorrhage?; in Anonymous Stroke: A Practical Guide to Management. Oxford: Blackwell Science Ltd, 1996, pp $322-359$.

7 Schievink WI, Schaid DJ, Rogers HM, Piepgras DG, Michels VV: On the inheritance of intracranial aneurysms. Stroke 1994; 25: $2028-2037$.

8 Chambers WR, Harper BFj, Simpson JR: Familial incidence of congenital aneurysms of cerebral arteries. JAMA 1954; 135: 358-359.

9 Bromberg JEC, Rinkel GJE, Algra A et al: Hypertension, stroke, and coronary heart disease in relatives of patients with subarachnoid hemorrhage. Stroke 1996; 27: 7-9.

10 Schievink WI, Limburg M, Dreissen JJR, Peeters FLM, ter Berg HWM: Screening for unruptured familial:intracranial aneurysms: subarachnoid hemorrhage 2 years after angiography negative for aneurysms. Neurosurgery 1991; 29: 434-437, discussion 437-438.

11 Endtz LJ: Familial incidence of intracranial aneurysms. Acto Neurochir 1968; 19: 297-305.

12 ter Berg HWM, Bijlsma JB, Veiga Pires JA et al: Familial association of intracranial aneurysms and multiple congenital anomalies. Arch Neurol 1986; 43: 30-33.

13 Schievink WI: Genetics of intracranial aneurysms. Neurosurgery 1997; 40: 651-662, discussion 662-663.

14 Ronkainen A, Hernesniemi J, Ryynanen M: Familial subarachnoid hemorrhage in east Finland, 1977-1990. Neurosurgery 1993; 33: 787-796, discussion 796-799.

15 Nakajima $\mathrm{H}$, Kishi $\mathrm{H}$, Yasui $\mathrm{T}$ et al: Intracranial aneurysms in identical twins. Surg Neurol 1998; 49: 306-308.

16 Ronkainen A, Miettinen H, Karkola $\mathrm{K}$ et al: Risk of harboring an unruptured intracranial aneurysm. Stroke 1998; 29: 359-362.

17 Rinkel GJE, Djibuti M, van Gijn J: Prevalence and risk of rupture of intracranial aneurysms: a systematic review. Stroke 1998; 29: $251-256$.

18 Kojima M, Nagasawa S, Lee YE et al: Asymptomatic familial cerebral aneurysms. Neurosurgery 1998; 43: 776-781.

19 Fox JL, Ko JP: Familial intracranial aneurysms. Six cases among 13 siblings. J Neurosurg 1980; 52: 501-503.

20 Fox JL: Familial intracranial aneurysms. Case report. J Neurosurg 1982; 57: 416-417.

21 Patrick D, Appleby A: Familial intracranial aneurysm and infundibular widening. Neuroradiology 1983; 25: 329-334.

22 Raaymakers TW, Rinkel GJE, Ramos LM: Initial and follow-up screening for aneurysms in families with familial subarachnoid hemorrhage. Neurology 1998; 51: 1125.

23 Locksley HB, Sahs AL, Knowler L: Report on the cooperative study of intracranial aneurysms and subarachnoid hemorrhage. Section II. General survey of cases in the central registry and characteristics of the sample population. J Neurosurg 1966; 24: 922-932.

24 Bentzen N: Family incidence of intracranial aneurysms: case reports. NZ Med J 1972; 75: 153-155.

25 Verdura J, Resnikoff S, Rosenthal J, Cardenas J: Familial intracranial aneurysms, with two occurring at the distal anterior cerebral artery. Neurosurgery 1983; 12: 214-216.

26 ter Berg HWM, Dippel DWJ, Limburg M, Schievink WI, van Gijn J: Familial intracranial aneurysms. A review. Stroke 1992; 23: $1024-1030$

27 Edelsohn L, Caplan L, Rosenbaum AE: Familial aneurysms and infundibular widening. Neurology 1972; 22: 1056-1060.

28 Shinton R, Palsingh J, Williams B: Cerebral haemorrhage and berry aneurysm: evidence from a family for a pattern of autosomal dominant inheritance. J Neurol Neurosurg Psychiatry 1991; 54: 838-840.

29 Acosta-Rua GJ: Familial incidence of ruptured intracranial aneurysms. Report of 12 cases. Arch Neurol 1978; 35: 675-677.

30 Evans TW, Venning MC, Strang FA, Donnai D: Dominant inheritance of intracranial berry aneurysm. Br Med J Clin Res Ed 1981; 283: 824-825. 
31 Brodsky MC, Frenkel RE, Spoor TC: Familial intracranial aneurysm presenting as a subtle stable third nerve palsy. Case report. Arch Ophthalmol 1988; 106: 173.

32 Elshunnar KS, Whittle IR: Familial intracranial aneurysms: report of five families. Br I Neurosurg 1990; 4: 181-186.

33 Chakravorty B, Gleadhill CA: Familial incidence of cerebral aneurysms. Br Med J 1966; 5480: 147-148.

34 Nagae K, Goto I, Ueda K, Morotomi Y: Familial occurrence of multiple intracranial aneurysms. Case report. J Neurosurg 1972; 37: 364-367.

35 Morooka Y, Waga S: Familial intracranial aneurysms: report of four families. Surg Neurol 1983; 19: 260-262.

36 Maroun FB, Murray GP, Jacob JC, Mangan MA, Faridi M: Familial intracranial aneurysms: report of three families. Surg Neurol 1986; 25: $85-88$
37 Jaksche H: Familiäre Aneurysmen. Vier Karotisaneurysmen aus einer zehnköpfigen Familie. Zentralbl Neurochir 1986; 47: $351-353$.

38 Ambrosetto P, Galassi E: Familial occurrence of multiple intracranial aneurysms. Case reports and review of the literature. Acta Neurochir 1981; 56: 233-238.

39 Jain KK: Familial intracranial aneurysms. Review of literature and presentation of six new cases. Acta Neurochir 1974; 30: $129-137$.

40 Leblanc R, Melanson D, Tampieri D, Guttmann RD: Familial cerebral aneurysms: a study of 13 families. Neurosurgery 1995; 37: 633-638, discussion 638-639.

41 Brisman R, Abbassioun K: Familial intracranial aneurysms. J Neurosurg 1971; 34: 678-682. 